\title{
Efeito da desmama precoce na eficiência reprodutiva de vacas Guzerá ${ }^{1}$
}

\author{
Keny Samejima Mascarenhas Lopes ${ }^{2}$, Kazuo Leonardo Almeida Yokobatake², \\ Vanessa Veronese Ortunho ${ }^{2}$, Nídia Raquel Costa ${ }^{3}$, Hélio Takachi Okuda ${ }^{2}$
}

\begin{abstract}
Effect of early weaning on the reproductive efficiency of Guzerá cows

The early weaning method is an alternative to increase the body weight of calves, since it is based on the total or temporary interruption of suckling by animals, in an attempt to faster develop the rumen of those receiving milk ad libitum. Thus, this study was conducted in Selvíria, Mato Grosso do Sul State, Brazil, in order to evaluate the weight gain of calves subjected to two weaning methods (conventional, i.e., calves were kept with cows, and controlled, where calves had access to suckling for one hour per day), as well as body condition and pregnancy rate of Guzerá primiparous and multiparous cows. Once a month, the animals were weighed, in order to measure their weight gain. At the birth and definite weaning of calves, the cows had their body condition evaluated, as well as their pregnancy rate, at the end of weaning. It was found that the controlled weaning method showed no significant difference, however, it becomes feasible in the beef cattle chain, since it can reduce the delivering intervals, due to the improved body condition of cows, especially in times of drought, when there is low food availability. An increase in the weight of calves at weaning was also observed for primiparous cows.
\end{abstract}

KEY-WORDS: Calves; body condition; beef cattle; pregnancy rate.

\section{INTRODUÇÃO}

A bovinocultura de corte brasileira tem passado por extensas transformações, nas últimas décadas, devido a diversos fatores, tais como competição com outras fontes de proteína animal, adequação da cadeia produtiva às exigências do mercado interno e externo e problemas de ordem sanitária.

O País, situado quase que por completo nas regiões tropical e subtropical, possui alterações sazonais, com períodos de chuvas regulares e tem-

\section{RESUMO}

O sistema de desmama precoce é uma alternativa para aumentar o peso corporal de bezerros, uma vez que se fundamenta na interrupção total ou temporária do aleitamento dos animais, na tentativa de desenvolver, mais rapidamente, o rúmen daqueles que recebem leite ad libitum. Assim, este trabalho foi realizado em Selvíria (MS), com o objetivo de avaliar o ganho de peso de bezerros submetidos a dois manejos de desmama (convencional, ou seja, na permanência dos bezerros com as vacas, e controlada, em que os bezerros tinham acesso à amamentação durante somente uma hora por dia), bem como o escore corporal e a taxa de prenhez de vacas primíparas e multíparas da raça Guzerá. Uma vez, a cada mês, os animais foram pesados, a fim de aferir o ganho de peso. No nascimento e na desmama definitiva, o escore corporal das vacas foi avaliado, assim como a taxa de prenhez, ao término da desmama. Constatou-se que o método de desmama controlada não apresentou diferença significativa, porém, torna-se viável na cadeia de gado de corte, uma vez que pode diminuir o intervalo de partos, devido à melhora na condição corporal das vacas, principalmente em épocas de seca em que há baixa disponibilidade de alimento. Houve, também, aumento de peso dos bezerros na desmama, para vacas primíparas.

PALAVRAS-CHAVE: Bezerros; escore corporal; gado de corte; taxa de prenhez.

peraturas elevadas e períodos de ausência de chuvas com temperaturas mais amenas. De maneira geral, os animais de corte ganham peso no período de abundância de pastagens e perdem peso no período crítico do ano (Amaral 2001).

O Brasil apresentava, em 2012, efetivo de rebanho bovino de 211.279.082 cabeças (IBGE 2012 b). No $3^{\circ}$ trimestre de 2012, o País obteve recorde de abate de bovinos, atingindo 8.027 milhões de cabeças, superando, em 5,0\%, o trimestre anterior (IBGE 2012a). Estima-se que, em 2016, a produção

1. Trabalho recebido em nov./2012 e aceito para publicação em nov./2013 ( $\mathrm{n}^{\mathrm{o}}$ registro: PAT 21057).

2. Universidade Estadual Paulista "Júlio de Mesquita Filho" (Unesp), Faculdade de Engenharia, Departamento de Biologia e Zootecnia, Ilha Solteira, SP, Brasil.E-mails: keny.samejima@gmail.com,kazuo.yokobatake@gmail.com, vanessaverort@yahoo.com.br, okuda@bio.feis.unesp.br.

3. Universidade Estadual Paulista "Júlio de Mesquita Filho" (Unesp), Faculdade de Engenharia, Departamento de Fitossanidade, Engenharia Rural e Solos, Ilha Solteira, SP, Brasil.E-mail: nidiarcosta@gmail.com. 
de carne bovina alcance 9.531 mil toneladas (Brasil 2013). Para isto, há necessidade de produzir novilhos precoces e/ou superprecoces, ou seja, elevar o peso de desmama destes animais. Com isto, pecuaristas acreditam no sistema de desmama precoce, recurso utilizado para a obtenção de bezerros com pesos mais elevados, após a desmama.

Para isso, métodos como o creep-feeding e/ ou creep-grazing (local com acesso exclusivo dos bezerros à alimentação) têm se mostrado de grande importância aos produtores, uma vez que apresentam melhores resultados de peso, à época da desmama. No entanto, observa-se um grande impacto no desempenho dos bezerros, quando são submetidos ao corte drástico da amamentação, quando muito jovens, por não se apresentarem completamente capacitados à digestão de alimentos volumosos, em virtude de não estarem com o rúmen completamente desenvolvido (Embrapa 1996).

Assim, o presente trabalho objetivou avaliar o ganho de peso de bezerros submetidos a dois manejos de desmama, bem como o escore corporal e a taxa de prenhez de vacas primíparas e multíparas da raça Guzerá.

\section{MATERIAL E MÉTODOS}

O trabalho foi conduzido na Fazenda de Ensino, Pesquisa e Extensão - Produção Animal da Faculdade de Engenharia da Universidade Estadual Paulista (Unesp), Campus de Ilha Solteira, no município de Selvíria, MS $\left(20^{\circ} 18^{\prime} \mathrm{S}, 51^{\circ} 22^{\prime} \mathrm{W}\right.$ e altitude de $370 \mathrm{~m}$ ).

A classificação climática, segundo Köppen, é Aw, ou seja, tropical úmido, com estação chuvosa no verão e seca no inverno. O estudo teve duração de nove meses, sendo setembro e outubro de 2011 os meses de parição das vacas e maio de 2012 o mês da avaliação de taxa de prenhez, no período chuvoso.

$\mathrm{O}$ delineamento experimental utilizado foi inteiramente casualizado, com dois tratamentos e dez repetições. Foram utilizadas 20 vacas da raça Guzerá, com seus respectivos bezerros, distribuídos, aleatoriamente, em dois manejos de amamentação: desmama convencional e desmama controlada. $\mathrm{Na}$ fazenda, os nascimentos concentraram-se entre 05/09/2011 e 05/10/2011, pois a estação de monta é realizada entre os meses de dezembro e janeiro de cada ano, por meio de inseminação artificial. Os bezerros apresentaram pesos médios, ao nascimento, de 29,00-31,40 kg (Tabela 1).
Tabela 1. Peso (kg), ao nascimento, dos bezerros submetidos à desmama controlada e convencional (Selvíria, MS, 2011).

\begin{tabular}{lcc}
\hline \multicolumn{1}{c}{ Desmama } & Multípara & Primípara \\
\hline Convencional & 30,40 & 30,80 \\
Controlada & 31,40 & 31,40 \\
\hline CV $(\%)$ & 10,36 & 14,79 \\
\hline
\end{tabular}

As vacas foram selecionadas 30 dias após o parto, sendo a escolha das fêmeas multíparas feita ao acaso, tanto para a desmama convencional quanto para a desmama controlada. No entanto, a escolha das vacas primíparas ocorreu de acordo com a disponibilidade da fazenda. Decorridos os trinta dias após o parto, as vacas e os bezerros foram encaminhados para dois piquetes de Urochloa brizantha cv. Xaraés, com lotação aproximada de duas UA ha ${ }^{-1}$, onde foram mantidos até a avaliação de taxa de prenhez das vacas. Os dois tratamentos foram constituídos por dez vacas, sendo cinco primíparas e cinco multíparas, as quais foram consideradas unidades experimentais, assim como os bezerros.

$\mathrm{Na}$ desmama convencional, os bezerros foram mantidos junto às vacas e um touro, sendo a relação touro:vaca de 1:10, da mesma raça, em pasto de Urochloa brizantha cv. Xaraés, entre outubro de 2011 e maio de 2012. Para a suplementação dos bezerros, foi utilizado um sistema de creep-feeding, com medidas que permitiam acesso exclusivo dos bezerros ao concentrado formulado com $35 \%$ de farelo de soja, $63 \%$ de milho e $2 \%$ de sal mineral. Esta suplementação foi fornecida desde o início do experimento (31/10/2011), disponibilizando-se, aproximadamente, $1,0 \mathrm{~kg} \mathrm{dia}^{-1}$ bezerro ${ }^{-1}$.

Para o tratamento de desmama com controle de amamentação, as vacas, bezerros e o touro foram mantidos em pastos de Urochloa brizantha cv. Xaraés, entre outubro de 2011 e maio de 2012. Logo após serem encaminhados ao pasto, os bezerros de um mês de idade foram separados das vacas e conduzidos para um piquete vizinho, sem acesso às respectivas progenitoras. Os bezerros foram submetidos a uma amamentação diária, às 7 horas da manhã, durante uma hora, e suplementados com concentrado $\left(1,0 \mathrm{~kg} \mathrm{dia}^{-1}\right.$ bezerro $\left.^{-1}\right)$ em comedouros, sem o uso do creep-feeding.

No início do experimento, os bezerros foram pesados, assim como as vacas, avaliando-se, também, o escore corporal (1 - muito magra e 9 - muito gorda), no início e término do período, sendo estas operações 
realizadas por um técnico treinado. Para a avaliação de ganho de peso dos animais, foram realizadas pesagens a cada 28 dias, totalizando cinco mensurações. As avaliações de taxa de prenhez das vacas foram realizadas aos 45 dias após a retirada dos touros dos dois tratamentos, na última pesagem, por meio de apalpação retal, realizada por um médico veterinário.

Para os cálculos de ganho de peso diário, entre cada pesagem, utilizou-se a fórmula ganho de peso $=\mathrm{GPP} / \mathrm{T}$, em que GPP $=$ ganho de peso entre as pesagens e $\mathrm{T}=$ tempo de 30 dias, ou seja, entre as pesagens.

O ganho de peso total foi calculado da seguinte maneira: ganho de peso total $=\mathrm{GP} / \mathrm{Tt}$, em que $\mathrm{GP}=$ ganho de peso durante todo o período experimental e $\mathrm{Tt}=$ duração total das pesagens dos animais.

Os resultados foram submetidos à análise de variância, pelo teste $\mathrm{F}(\mathrm{p}<0,05)$, e as médias dos atributos comparadas pelo teste Tukey $(\mathrm{p}<0,05)$, sendo avaliadas, separadamente, as vacas primíparas e multíparas. A análise estatística foi realizada utilizando-se o software estatístico Sisvar (Ferreira 1999).

\section{RESULTADOS E DISCUSSÃO}

Verificou-se, durante as pesagens consecutivas realizadas a cada mês, em bezerros de vacas primíparas (Tabela 2), diferença estatística no período inicial do experimento, uma vez que a escolha das vacas utilizadas na presente pesquisa ocorreu ao acaso. $\mathrm{Na}$ terceira pesagem, observou-se que os animais submetidos ao tratamento de desmama controlada atingiram maiores pesos, quando comparado ao tratamento de desmama convencional. Tal fato associa-se à pouca disponibilidade de leite durante o dia, fazendo com que os animais procurassem outra fonte de alimento, alimentando-se, portanto, da gramínea fornecida por meio da pastagem e do alimento concentrado e, consequentemente, iniciando, mais rapidamente, o desenvolvimento do sistema digestivo (rúmen) dos bezerros mantidos ao pé das vacas.

Os menores valores de ganho de peso e peso dos bezerros submetidos ao tratamento de desmama convencional associaram-se à baixa habilidade materna de vacas primíparas e à menor produção de leite, pois as glândulas mamárias de tais animais, possivelmente, não estavam totalmente desenvolvidas. Segundo Schmidek (2004), vacas de primeira cria possuem inexperiência materna, ou seja, maiores abandonos, atrasos ou falhas na mamada dos bezerros, além de produzirem bezerros mais leves ao nascer e apresentarem menor produção de leite, maiores índices de distocia e natimortos e menores níveis de imunoglobulinas no leite.

Quando observadas as médias de ganho de peso diário entre cada pesagem e o ganho de peso diário total do período de realização do experimento (GPT) (Tabela 2), não foram observadas diferenças significativas $(p>0,05)$ entre os animais avaliados. Porém, observou-se que, no primeiro mês, o ganho de peso dos animais submetidos à desmama controlada foi menor, o que pode estar relacionado ao corte drástico do aleitamento diário destes animais.

Devido a essa redução de ganho de peso, no primeiro mês de avaliação, os animais submetidos à desmama convencional obtiveram ganho de peso diário total maior que aqueles submetidos à desmama controlada, confirmando valores encontrados por Strack et al. (2003), os quais observaram melhores resultados, em relação ao GMD, para animais mantidos ao pé das vacas, sendo estes valores de $650,0 \mathrm{~g} \mathrm{dia}^{-1} \mathrm{e}$ $621,0 \mathrm{~g} \mathrm{dia}^{-1}$, para animais mantidos ao pé das vacas e com amamentação controlada, respectivamente. Após o primeiro mês, os animais do presente trabalho retomaram o ganho de peso, mostrando superiorida-

Tabela 2. Valores médios para peso, ganho de peso em cada mês e ganho de peso diário durante todo o experimento (GPT) de bezerros de vacas primíparas $(\mathrm{kg})$ da raça Guzerá submetidos à desmama controlada e convencional, durante cada mês do experimento (Selvíria, MS, 2011/2012).

\begin{tabular}{|c|c|c|c|c|c|c|c|c|c|c|}
\hline \multirow{2}{*}{ Desmama } & \multicolumn{5}{|c|}{ Peso $\longrightarrow$} & \multicolumn{4}{|c|}{ Ganho de peso após } & \multirow{2}{*}{ GPT } \\
\hline & $1^{\circ}$ mês & $2^{\circ}$ mês & $3^{\circ}$ mês & $4^{\circ}$ mês & $5^{\circ}$ mês & $2^{\circ}$ mês & $3^{\circ}$ mês & $4^{\circ}$ mês & $5^{\circ}$ mês & \\
\hline Convencional & $44,60 \mathrm{~b}$ & 63,00 & $80,40 \mathrm{~b}$ & 116,00 & 141,80 & 0,613 & 0,580 & 1,187 & 0,860 & 0,804 \\
\hline Controlada & $65,00 \mathrm{a}$ & 75,60 & $94,60 \mathrm{a}$ & 130,20 & 159,40 & 0,353 & 0,633 & 1,187 & 0,973 & 0,780 \\
\hline CV $(\%)$ & 16,13 & 16,81 & 8,64 & 13,88 & 12,77 & 39,37 & 32,08 & 31,19 & 13,90 & 13,66 \\
\hline Teste F & $*$ & $\mathrm{~ns}$ & $*$ & $\mathrm{~ns}$ & $\mathrm{~ns}$ & ns & $\mathrm{ns}$ & $\mathrm{ns}$ & $\mathrm{ns}$ & $\mathrm{ns}$ \\
\hline
\end{tabular}

** e ns: $(\mathrm{p}<0,01)$ e $(\mathrm{p}>0,05)$, respectivamente. 
de numérica, em relação aos bezerros mantidos em desmama convencional.

Moletta et al. (2003b), em estudo de desempenho de bezerros de vacas primíparas mestiços de Purunã, submetidos a uma mamada diária, encontraram valores para ganho de peso e peso na desmama de $616,23 \mathrm{~g}$ e $178,41 \mathrm{~kg}$, respectivamente. Para valores de ganho de peso, os resultados obtidos no presente trabalho foram superiores aos apresentados por Moletta et al. (2003b). Já para o peso na desmama, os valores encontrados foram inferiores aos observados pelos autores. Entretanto, Nogueira et al. (2006) avaliaram o desempenho de bezerros de vacas primíparas da raça Nelore, submetidos à suplementação com sistema de creep-feeding, e observaram ganho médio de peso de $0,64 \mathrm{~kg}$, durante o período, e peso na desmama de $163,83 \mathrm{~kg}$, valores abaixo dos encontrados no presente trabalho.

Em relação ao peso dos bezerros de vacas multíparas, não foram observadas diferenças significativas em cada pesagem (Tabela 3). Porém, observando-se a média de ganho de peso diário dos bezerros, verificou-se diferença estatística no segundo e último mês do experimento, sendo que os maiores valores foram obtidos para os animais que receberam, como tratamento, a desmama convencional.

A diferença estatística, no segundo mês, pode estar relacionada ao corte drástico na amamentação dos bezerros em desmama controlada. Já no terceiro mês, os animais retomaram o ganho de peso, porém, de maneira insuficiente para superar o ganho de peso dos animais em desmama convencional. Os maiores valores de ganho de peso dos bezerros em amamentação convencional associam-se ao maior cuidado da progenitora com o bezerro e à sua maior produção e melhor qualidade de leite, em relação a vacas de primeira cria.

Claro Júnior et al. (2010) observaram pesos na desmama, aos 205 dias, em bezerros (machos e fêmeas) de vacas multíparas da raça Nelore, com amamentação controlada (15 min. dia $\left.{ }^{-1}\right)$ e amamentação ao pé das vacas (ad libitum), de 164,1 kg e $161,9 \mathrm{~kg}$ e de $158,3 \mathrm{~kg}$ e $153,7 \mathrm{~kg}$, respectivamente, sendo estes valores para bezerros amamentados ao pé das vacas próximos aos encontrados no presente trabalho e, para animais com amamentação controlada, pesos mais elevados.

Bartz \& Gottschall (2004) avaliaram o desempenho de bezerros de cruza de Nelore, Aberdeen Angus e Charolês, submetidos a aleitamento interrompido e desmama convencional, tendo encontraram pesos, ao desmame, para bezerros com aleitamento interrompido, de $212,6 \mathrm{~kg}$ e, para animais em desmama convencional, de $208,6 \mathrm{~kg}$, valores diferentes dos encontrados no presente trabalho, uma vez que os bezerros em desmama controlada obtiveram menores pesos ao desmame.

Bartz \& Gottschall (2004) verificaram, ainda, valores de ganho de peso diário, do nascimento à desmama, de $0,848 \mathrm{~kg}$ e $0,864 \mathrm{~kg}$, para aleitamento interrompido e desmama convencional, respectivamente, corroborando os valores obtidos na presente pesquisa, em que os valores médios de ganho de peso diário, no período de realização do experimento, foram menores para os animais que receberam, como tratamento, a desmama controlada (Tabela 3).

De maneira geral, não houve diferenças significativas, quanto ao peso médio das vacas primíparas obtido durante cada mês de avaliação do experimento (Tabela 4). Todavia, nos primeiros dois meses, as vacas que receberam o tratamento de desmama controlada obtiveram, numericamente, os menores valores, podendo este fato estar relacionado ao estresse causado pela retirada brusca dos bezerros, sendo esta posição invertida a partir da terceira pesagem. Esta inversão no ganho de peso relaciona-se às necessidades de as vacas do

Tabela 3. Valores médios de peso, ganho de peso em cada mês e ganho de peso diário durante todo o experimento (GPT) de bezerros de vacas multíparas $(\mathrm{kg})$ da raça Guzerá submetidos à desmama controlada e convencional, durante cada mês do experimento (Selvíria, MS, 2011/2012).

\begin{tabular}{|c|c|c|c|c|c|c|c|c|c|c|}
\hline \multirow{2}{*}{ Desmama } & \multicolumn{5}{|c|}{$\longrightarrow$ Peso $\longrightarrow$} & \multicolumn{4}{|c|}{ Ganho de peso após } & \multirow{2}{*}{ GPT } \\
\hline & $1^{\circ}$ mês & $2^{\circ}$ mês & $3^{\circ}$ mês & $4^{\circ}$ mês & $5^{\circ}$ mês & $2^{\circ}$ mês & $3^{\circ}$ mês & $4^{\circ}$ mês & $5^{\circ}$ mês & \\
\hline Convencional & 53,40 & 70,20 & 89,00 & 126,40 & 155,00 & 0,560 & $0,627 \mathrm{a}$ & 1,247 & $0,954 \mathrm{a}$ & 0,840 \\
\hline Controlada & 61,40 & 76,60 & 84,80 & 124,00 & 146,80 & 0,507 & $0,273 \mathrm{~b}$ & 1,307 & $0,760 \mathrm{~b}$ & 0,706 \\
\hline $\mathrm{CV}(\%)$ & 17,64 & 22,50 & 19,41 & 19,30 & 17,35 & 42,88 & 9,54 & 22,30 & 9,81 & 18,08 \\
\hline Teste F & ns & ns & ns & ns & ns & ns & $* *$ & ns & $*$ & ns \\
\hline
\end{tabular}


Tabela 4. Peso e ganho de peso durante o período experimental (GP) das vacas primíparas (kg) da raça Guzerá submetidas à desmama convencional e controlada (Selvíria, MS, 2011/2012).

\begin{tabular}{|c|c|c|c|c|c|c|}
\hline \multirow{2}{*}{ Desmama } & \multicolumn{5}{|c|}{ Peso } & \multirow{2}{*}{ GP } \\
\hline & $1^{\circ}$ mês & $2^{\circ}$ mês & $3^{\circ}$ mês & $4^{\circ}$ mês & $5^{\circ}$ mês & \\
\hline Convencional & 338,00 & 338,00 & 342,20 & 343,40 & 360,80 & $22,80 \mathrm{~b}$ \\
\hline Controlada & 312,00 & 318,20 & 344,20 & 378,20 & 402,20 & $90,20 \mathrm{a}$ \\
\hline CV (\%) & 8,33 & 4,86 & 4,14 & 6,54 & 7,26 & 15,33 \\
\hline Teste F & $\mathrm{ns}$ & $\mathrm{ns}$ & $\mathrm{ns}$ & $\mathrm{ns}$ & $\mathrm{ns}$ & * \\
\hline
\end{tabular}

tratamento de desmama convencional suprirem as exigências nutricionais para a produção de leite, pois os bezerros foram mantidos ao pé, sob lactação ad libitum. Para as vacas que receberam o tratamento de desmama controlada, não ocorreu tal fato, devido à isenção do estímulo contínuo da amamentação pelos bezerros, fazendo com que sua alimentação fosse voltada ao ganho de peso e não para a produção de leite, o que pode ser confirmado observando-se o ganho de peso das vacas durante todo o período experimental (Tabela 4), sendo este dado significativo $(\mathrm{p}<0,05)$, para as vacas primíparas sob desmama controlada, com ganho de peso de 90,20 kg. Já as vacas em desmama convencional obtiveram $22,80 \mathrm{~kg}$.

Segundo Almeida et al. (2002), para que vacas apresentem um bom desempenho reprodutivo, devem ter, no início do acasalamento, pesos entre $380 \mathrm{~kg}$ e $400 \mathrm{~kg}$. No presente trabalho, tanto para vacas primíparas (Tabela 4) quanto para vacas multíparas (Tabela 6), observaram-se pesos próximos ou dentro desta faixa, principalmente para vacas submetidas à desmama controlada.

A recuperação metabólica e fisiológica dos animais, no período pós-parto, deixando a produção de leite para o ganho de peso, faz com que as vacas atinjam condições corporais mais rapidamente, favorecendo um possível retorno ao cio adiantado, de modo a diminuir o período entre partos e tornar a cadeia mais produtiva.
Tabela 5. Escore corporal das vacas primíparas da raça Guzerá submetidas à desmama convencional e controlada (Selvíria, MS, 2011/2012).

\begin{tabular}{|c|c|c|}
\hline Desmama & Primeira & Última \\
\hline Convencional & $3,80 \mathrm{a}$ & 4,80 \\
\hline Controlada & $2,40 \mathrm{~b}$ & 5,80 \\
\hline CV (\%) & 12,49 & 28,30 \\
\hline Teste $\mathrm{F}$ & $* *$ & ns \\
\hline
\end{tabular}

** e ns: $(p<0,01)$ e $(p>0,05)$, respectivamente.

Em relação ao escore corporal (Tabela 5) das vacas primíparas, houve diferença significativa apenas na primeira avaliação. Cabe ressaltar que a escolha das vacas foi ao acaso, com as vacas dos tratamentos com desmama convencional possuindo maiores valores de escore corporal (Tabela 5). Entretanto, ao final do experimento, as vacas do tratamento de desmama controlada apresentaram melhores condições corporais, por não terem o estímulo contínuo de amamentação dos bezerros. Desta maneira, os nutrientes ingeridos durante a alimentação, por estes animais, direcionaram-se à produção de massa corporal.

Nogueira et al. (2006) avaliaram dois tratamentos com vacas primíparas com bezerros ao pé, sem e com suplementação em creep-feeding, no período seco do ano, e observaram escore corporal, taxa de prenhez e peso das vacas variando $4,23-4,65 ; 4,05-4,86 ; 28,8-42,0 \% ; 282,78-291,57 \mathrm{~kg}$;

Tabela 6. Peso e ganho de peso durante o período experimental (GP) das vacas multíparas (kg) da raça Guzerá submetidas à desmama convencional e controlada (Selvíria, MS, 2011/2012).

\begin{tabular}{|c|c|c|c|c|c|c|}
\hline \multirow{2}{*}{ Desmama } & \multicolumn{5}{|c|}{ Peso } & \multirow{2}{*}{ GP } \\
\hline & $1^{\circ}$ mês & $2^{\circ}$ mês & $3^{\circ}$ mês & $4^{\circ}$ mês & $5^{\circ}$ mês & \\
\hline Convencional & 404,60 & 406,60 & 418,40 & 431,60 & 443,00 & $38,40 \mathrm{~b}$ \\
\hline Controlada & 417,60 & 416,20 & 447,80 & 473,80 & 492,40 & $74,80 \mathrm{a}$ \\
\hline $\mathrm{CV}(\%)$ & 7,28 & 8,80 & 8,32 & 9,11 & 8,31 & 18,21 \\
\hline Teste $\mathrm{F}$ & ns & $\mathrm{ns}$ & $\mathrm{ns}$ & $\mathrm{ns}$ & ns & $*$ \\
\hline
\end{tabular}


e $283,07-299,23 \mathrm{~kg}$, respectivamente. O valor do escore corporal final das vacas do desmame ao pé com suplementação aproximou-se do encontrado no presente trabalho, porém, os pesos das vacas foram menores.

Lobato et al. (2000) observaram o efeito da idade de desmama (3 e 7 meses), em vacas primíparas de cruzas zebuínas e taurinas. Durante o experimento, encontraram valores para peso das vacas e condições corporais variando 405,1-399,1 kg e $4,22-3,87$, respectivamente para vacas submetidas à desmama convencional e bezerros de 176 dias de idade mantidos com as progenitoras. Para vacas submetidas à desmama precoce e bezerros com 70 dias de idade, obtiveram valores de 400,1-417,6 kg e 4,21-4,08, respectivamente para peso e condição corporal. Assim, concluíram que vacas de cruzas zebuínas, em método de desmama precoce, obtêm maiores ganhos de peso, além de diminuição do intervalo entre partos. Tais valores de peso e condição corporal corroboram os resultados encontrados no presente trabalho, em que observou-se o mesmo comportamento, confirmando que o uso do método de desmama precoce é viável ao sistema de produção de gado de corte.

De acordo com o peso obtido em cada mês de avaliação das vacas multíparas, não houve diferença significativa entre os tratamentos (Tabela 6). Porém, vacas submetidas ao tratamento de desmama controlada mantiveram pesos superiores, quando comparados aos das vacas em desmama convencional, obtendo-se recuperação pós-parto mais rápida e apresentando vantagem ao sistema produtivo, uma vez que vacas com melhores condições corporais estão mais aptas para uma nova gestação.

Houve diferença significativa $(\mathrm{p}<0,05)$ para o ganho de peso, durante o período experimental (Tabela 6), sendo maior para as vacas submetidas à desmama controlada, com ganho de $74,80 \mathrm{~kg}$, sendo este de $38,40 \mathrm{~kg}$, para as vacas em desmama convencional. Para as condições de escore corporal, houve diferença significativa na última avaliação, para as vacas submetidas ao tratamento de desmama controlada, o que pode estar relacionado ao menor estímulo de produção de leite para os bezerros (Tabela 7).

Almeida et al. (2002), em estudo sobre a desmama precoce aos 90 dias e desmama convencional aos 170 dias de idade, com vacas multíparas de cruza de Bos tauros x Bos indicus, observaram valores de peso das vacas e condição corporal de 402,1 kg e 2,4,
Tabela 7. Escore corporal das vacas multíparas da raça Guzerá submetidas à desmama convencional e controlada (Selvíria, MS, 2011/2012).

\begin{tabular}{lcc}
\hline \multirow{2}{*}{ Desmama } & \multicolumn{2}{c}{ Escore corporal } \\
\cline { 2 - 3 } & Primeira & Última \\
\hline Convencional & 4,00 & $5,20 \mathrm{~b}$ \\
Controlada & 4,00 & $6,80 \mathrm{a}$ \\
\hline CV $(\%)$ & 21,65 & 10,54 \\
\hline Teste $\mathrm{F}$ & $\mathrm{ns}$ & $*$ \\
\hline * e ns: $(\mathrm{p}<0,05)$ e $(\mathrm{p}>0,05)$, respectivamente.
\end{tabular}

respectivamente, para a desmama precoce. Já para a desmama convencional, os mesmos parâmetros apresentaram valores de $391,0 \mathrm{~kg}$ e 2,0, sendo estes inferiores aos encontrados no presente trabalho.

Almeida et al. (2002) avaliaram, também, a taxa de prenhez das vacas e obtiveram, em dois anos de estudo, para a desmama precoce, $40,0 \%$ e $51,4 \%$, no primeiro e segundo anos, respectivamente. Já para a desmama convencional, foram observadas taxas de $11,1 \%$ e $20,0 \%$, valores inferiores aos encontrados no presente trabalho, demonstrando que vacas submetidas a menor tempo com a presença dos bezerros e menores estímulos à produção de leite apresentaram maior taxa de prenhez, como apresentado neste trabalho (Tabela 8).

Na avaliação da taxa de prenhez (Tabela 8), realizada por apalpação retal do trato genital, por um médico veterinário, observou-se que as vacas multíparas apresentaram os melhores índices de prenhez, confirmando que a desmama controlada foi eficiente para vacas multíparas. Porém, para as vacas primíparas, verificou-se que não houve diferença na taxa de prenhez, em relação aos tratamentos, relacionando-se à necessidade de maior tempo para o retorno ao cio e, consequentemente, maior intervalo entre partos. Tal resultado poderia apresentar diferença significativa, se o tempo de permanência dos touros junto às vacas primíparas fosse maior.

Tabela 8. Taxa de prenhez (\%) das vacas multíparas e primíparas da raça Guzerá submetidas à desmama convencional e controlada (Selvíria, MS, 2012).

\begin{tabular}{lcc}
\hline \multirow{2}{*}{ Desmama } & \multicolumn{2}{c}{ Taxa de prenhez } \\
\cline { 2 - 3 } & Primípara & Multípara \\
\hline Convencional & 20,00 & $40,00 \mathrm{~b}$ \\
Controlada & 20,00 & $80,00 \mathrm{a}$ \\
\hline CV $(\%)$ & 20,82 & 25,36 \\
\hline Teste $\mathrm{F}$ & ns & $* *$ \\
\hline$*$ e e ns: $(\mathrm{p}<0,01)$ e $(\mathrm{p}>0,05)$, respectivamente. &
\end{tabular}


Segundo Amaral (2001), após o parto, há diminuição no funcionamento eixo hipotálamo-hipófise, ovário e útero, diminuindo, assim, a concentração de hormônio luteinizante (LH). Consequentemente, há predominância da progesterona, que é intensificada com a mamada dos bezerros, evitando o retorno do cio e diminuindo o desempenho reprodutivo.

Os resultados encontrados no presente trabalho são similares aos obtidos por Moletta et al. (2003a), que, também, afirmam que vacas primíparas não respondem, satisfatoriamente, ao método de amamentação controlada, respondendo melhor à desmama precoce associada a práticas de manejo. Segundo Menegaz (2006), o índice de prenhez de vacas primíparas com bezerros ao pé varia em torno de $18-22 \%$, estando os resultados obtidos no presente trabalho dentro destes valores.

Moletta et al. (2003a, 2003b), utilizando práticas de desmama controlada e convencional, tanto em vacas de primeira gestação como em vacas multíparas, encontraram valores de peso e taxa de prenhez elevados, assim como no presente trabalho, confirmando os resultados obtidos. Observaram pesos, para vacas Canchim multíparas e primíparas em controle de mamada e com bezerros ao pé, de 427,14 kg; 399,52 kg; 405,33 kg; e 399,06 kg, respectivamente (Moletta et al. 2003a), e taxas de prenhez de $69,6 \% ; 30,8 \% ; 12,5 \%$; e 13,51\%. Moletta et al. (2003b) verificaram pesos, ao final da estação de monta, para vacas primíparas e multíparas submetidas à amamentação controlada, de 399,97 kg e 400,00 kg, respectivamente, assim como taxa de prenhez de $16,6 \%$ e $88,0 \%$.

A utilização da desmama controlada em gado de corte demonstra diferença nos pesos dos bezerros, tanto para aqueles provenientes de vacas primíparas quanto para os provenientes de vacas multíparas.

Vacas multíparas submetidas à desmama controlada apresentaram recuperação de condição corporal mais rápida, em relação aos métodos convencionais de desmama, podendo ficar susceptíveis a uma nova prenhez, diminuindo, assim, o intervalo entre partos e otimizando a cadeia produtiva. Porém, para vacas primíparas, estes métodos não foram eficientes, uma vez que os índices de prenhez foram iguais entre os tratamentos, apesar de as vacas em desmama controlada atingirem condições corporais melhores e mais precocemente, com melhor ganho de peso.

O método de desmama controlada não apresentou diferença significativa no presente trabalho, ainda assim, mostrou-se viável para a cadeia de gado de corte, uma vez que pode diminuir o intervalo de partos, pois há melhora na condição corporal dos animais. Pode ser uma boa prática de manejo, principalmente em épocas de seca, quando há baixa disponibilidade de alimento, comprometendo a recuperação do peso e a condição corporal das fêmeas, as quais demandam grande aporte nutricional para a lactação de bezerros ao pé. Além disto, a mamada controlada pode permitir aumento no peso dos bezerros e vacas, após a desmama.

\section{CONCLUSÃO}

O método de desmama controlada não apresentou diferença significativa, porém, torna-se viável na cadeia de gado de corte, uma vez que pode diminuir o intervalo de partos, devido à melhora na condição corporal das vacas, principalmente em épocas de seca, quando há baixa disponibilidade de alimento, bem como aumento no peso dos bezerros na desmama, para vacas primíparas.

\section{REFERÊNCIAS}

ALMEIDA, L. S. P. et al. Data de desmame e desempenho reprodutivo de vacas de corte. Revista Brasileira de Zootecnia, Viçosa, v. 31, n. 3, p. 1223-1229, 2002.

AMARAL, T. B. Desempenho reprodutivo de vacas Nelore suplementadas ou não após o parto, com ou sem restrição da amamentação. 2001. 41 f. Dissertação (Mestrado em Medicina Veterinária) - Escola de Veterinária, Universidade Federal de Minas Gerais, Belo Horizonte, 2001.

BARTZ, C.; GOTTSCHALL, C. S. Avaliação da técnica de aleitamento interrompido e desmame convencional sobre o desempenho de terneiros de corte. Revista Veterinária em Foco, Canoas, v. 1, n. 2, p. 17-27, 2004.

CLARO JÚNIOR, I. et al. Efeito da frequência de amamentação sobre a taxa de ovulação após tratamento com desmame temporário $+\mathrm{GnRH}$, sobre a incidência de luteólise prematura no primeiro ciclo estral pós-parto e sobre o desempenho da progênie de vacas Nelore. Arquivo Brasileiro de Medicina Veterinária e Zootecnia, Belo Horizonte, v. 62, n. 2, p. 281-288, 2010.

EMPRESA BRASILEIRA DE PESQUISA AGROPECUÁRIA (Embrapa). Desmama em bovinos de corte. Campo Grande: Embrapa Gado de Corte, 1996.

FERREIRA, D. F. Sisvar: sistema de análise de variância. Lavras: UFLa/DEX, 1999. 
INSTITUTO BRASILEIRO DE GEOGRAFIA E ESTATÍSTICA (IBGE). Indicadores IBGE: estatística de produção pecuária. 2012a. Disponível em: <http://www. ibge.gov.br/home>. Acesso em: 24 mar. 2012.

INSTITUTO BRASILEIRO DE GEOGRAFIA E ESTATÍSTICA (IBGE). Tabelas de resultados IBGE: Tabela 1 - Efetivo dos rebanhos em 31.12 e variação anual, segundo as categorias: Brasil 2011-2012. 2012b. Disponível em: <ftp://ftp.ibge.gov.br/Producao_Pecuaria/ Producao_da_Pecuaria_Municipal/2012/tabelas_pdf/ tab01.pdf>. Acesso em: 22 nov. 2013.

LOBATO, J. F. P. et al. Efeitos da idade à desmama dos bezerros sobre o desempenho reprodutivo de vacas de corte primíparas. Revista Brasileira de Zootecnia, Viçosa, v. 29, n. 6, p. 2013-2018, 2000.

BRASIL. Ministério da Agricultura, Pecuária e Abastecimento (MAPA). Projeções do agronegócio: Brasil 2012/13 a 2022/23. 2013. Disponível em: <http:// www.agricultura.gov.br/arq_editor/projecoes $\% 20-\% 20$ versao\%20atualizada.pdf $>$. Acesso em: 22 nov. 2013.

MENEGAZ, A. L. Desempenho produtivo e reprodutivo de novilhas e vacas primiparas de corte. 2006. $183 \mathrm{f}$. Dissertação (Mestrado em Zootecnia) - Faculdade de Agronomia, Universidade Federal do Rio Grande do Sul, Porto Alegre, 2006.
MOLETTA, J. L. et al. Efeito da amamentação controlada, sobre o desempenho ponderal e reprodutivo de multíparas e primíparas. In: REUNIÃO DA SOCIEDADE BRASILEIRA DE ZOOTECNIA, 40., 2003, Santa Maria. Anais... Santa Maria: Sociedade Brasileira de Zootecnia, 2003a.

MOLETTA, J. L. et al. Desempenho de terneiros submetidos a uma mamada e um ou dois terneiros por vaca. In: REUNIÃO DA SOCIEDADE BRASILEIRA DE ZOOTECNIA, 40., 2003, Santa Maria. Anais... Santa Maria: Sociedade Brasileira de Zootecnia, 2003 b.

NOGUEIRA, E. et al. Efeito do creep-feeding sobre o desempenho de bezerros e a eficiência reprodutiva de primíparas Nelore, em pastejo. Arquivos Brasileiros de Medicina Veterinária e Zootecnia, Belo Horizonte, v. 58, n. 4, p. 607-613, 2006.

SCHMIDEK, A. Habilidade materna e aspectos relacionados à sobrevivência de bezerros: valores ótimos nem sempre são valores extremos. $A B C Z$, Uberaba, n. 21, p. $72-75,2004$.

STRACK, A. G. et al. Efeito da amamentação controlada, sobre o desempenho dos terneiros. In: REUNIÃO DA SOCIEDADE BRASILEIRA DE ZOOTECNIA, 40., 2003, Santa Maria. Anais... Santa Maria: Sociedade Brasileira de Zootecnia, 2003. 